\title{
Predictors of juvenile idiopathic arthritis course
}

\section{Jaryna J. Bojko', Ludmyla I. Omelczenko², Wiktor P. Czernyszow ${ }^{2}$}

${ }^{1}$ Lviv Regional Council Public Institution “Western Ukrainian Specialized Children's Medical Centre”, Lviv, Ukraine ${ }^{2}$ State Institution "Institute of Paediatrics, Midwifery and Gynaecology of the National Academy of Medical Sciences (NAMSc) of Ukraine", Kyiv, Ukraine

\begin{abstract}
Introduction: Juvenile idiopathic arthritis (JIA) is a heterogeneous group of inflammatory diseases of joints in children with various and often unfavourable prognosis. It is possible to improve the outcome of the disease in patients with JIA by a correct therapeutic choice made at disease onset - one that enables fast achievement of an inactive disease state and remission.

The aim of the investigation was to develop a model/application for automatic calculation of risk of treatment-refractory JIA taking into account the combined action of clinical and cytokine factors. Material and methods: Disease subtype was determined in 105 patients with JIA, as well as the number of poor prognostic factors and disease activity level. Blood serum cytokine levels (IL-1 $\beta$, IL-4, IL-6, IL-8, IL-10, IL-17, TNF- $\alpha$, IFN- $\gamma$ ) and their soluble receptors and agonists - interleukin 1 receptor agonist (IL-1Ra), soluble interleukin 2 receptor (sCD25), interleukin 6 (sIL6R), soluble tumour necrosis factor receptor 1 (STNFR1) - were determined in these patients using immunoenzymatic laboratory methods.

Results: The following prognostic factors were taken into account in the study: JIA subtype, disease activity, presence of clinically unfavourable factors and cytokine characteristics. We determined that systemic subtype of JIA, moderate and high disease activity, presence of factors of poor disease course and SCD25 and IL-6 levels are statistically significant factors of treatment-refractory disease course. A Microsoft Excel application was developed for automatic calculation of risk of treatment-refractory JIA in a specific patient based on 10 factors.

Conclusions: Use of an application for automatic calculation of risk of treatment-refractory JIA enables prediction of JIA disease course in patients at disease onset and personalization of the treatment protocol.
\end{abstract}

Key words: juvenile idiopathic arthritis, prognosis, refractory course, cytokines.

\section{Introduction}

Juvenile idiopathic arthritis (JIA) is a heterogeneous group of inflammatory diseases of joints in children with various and often unfavourable prognosis. It is possible to improve the outcome of the disease in patients with IIA by a correct therapeutic choice made at disease onset - one that enables fast achievement of an inactive disease state and remission. Not without reason is the concept of a "window of therapeutic opportunity", which defines a time frame within which an inactive state of the disease should be achieved in order to secure its favourable outcome, used in adult rheumatology. Investigations made over recent years proved that early beginning of aggressive treatment of the disease provides a better therapeutic response and outcome [1]. Early treatment of systemic JIA with interleukin-1 (IL-1) inhibitors appeared to be more successful than systemic steroid therapy [2]. In paediatric rheumatology time of methotrexate (MTX) therapy introduction proved to

\section{Address for correspondence:}

Jaryna J. Bojko, Lviv Regional Council Public Institution “Western Ukrainian Specialized Children's Medical Centre”, Lviv, Ukraine,

e-mail: jboyko@ukr.net

Submitted: 19.02.2015; Accepted: 15.06.2015 
be an important predictor of therapeutic response in patients with JIA [3]. Early commencement of aggressive therapy may improve long-term prognosis in JIA patients. On the other hand, application of aggressive treatment in children with JIA may produce a string of side effects, while the use of biological therapy is highly expensive. It should also be emphasized that not all children with JIA require aggressive treatment, as many of them may have favourable prognosis of the disease. As we see, for patients with JIA it is reasonable to define an individual prediction at the disease onset, which may enable an optimal choice of further treatment. It is important to create such methods of objective estimation of outcome and disease course in a particular JIA patient that may help, by evaluation of combined action of clinical and cytokine predictors, to forecast JIA course in certain patients.

The aim of the investigation was to develop a model/application for automatic calculation of risk of treatment-refractory JIA taking into account the combined action of clinical and cytokine factors.

\section{Material and methods}

Disease subtype was determined in 105 patients with JIA [4], as well as the number of poor prognostic factors and disease activity level according to the "Unified clinical protocol of medical help to children with juvenile arthritis in Ukraine" [5] and American College of Rheumatology (ACR) recommendations [6]. Blood serum cytokine levels (IL-1 $\beta$, IL-4, IL-6, IL-8, IL-10, IL-17, TNF- $\alpha$, IFN- $\gamma$ ) and their soluble receptors and agonists - interleukin 1 receptor agonist (IL-1Ra), soluble interleukin 2 receptor (SCD25), interleukin 6 (sIL-6R), soluble tumour necrosis factor receptor 1 (sTNF-R1) - were determined in these patients. Cytokine determination was performed using the immunoenzymatic method in the laboratory of immunology located at the Public Institute of Paediatrics, Midwifery and Gynaecology, NAMSc of Ukraine. Commercial test systems by BD Biosciences Pharmingen, San Diego, USA were used.

Two groups of patients were composed depending on the time of remission achievement. The first group consisted of 33 JIA patients with treatment-refractory JIA who did not achieve remission within 6 months of treatment with methotrexate at a dose of $15-20 \mathrm{mg} / \mathrm{m}^{2}$ (Table I). The second group consisted of 72 patients with JIA who achieved remission within the first 6 months of the disease.

All patients and their parents/guardians were informed about the aim of the study and gave consent to its conduction. The project of the study received a positive opinion of the Bioethical Committee at the Institute of Paediatrics, Midwifery and Gynaecology, NAMSc of Ukraine.

The software package STATISTICA 8.0 was used for statistical analyses of data. Comparison of rank and

Table I. Clinical features of JIA patients with refractory and non-treatment-refractory disease course

\begin{tabular}{|c|c|c|}
\hline Factors & $\begin{array}{l}\text { Patients with refractory } J \mathrm{~A} \\
\qquad N=33\end{array}$ & $\begin{array}{l}\text { Patients with non-refractory JIA } \\
\qquad N=72\end{array}$ \\
\hline Gender, M/F & $14 / 19$ & $39 / 33$ \\
\hline $\begin{array}{l}\text { Age at disease onset, median (min-max) } \\
\text { [lower-upper quartiles] }\end{array}$ & $\begin{array}{l}5.1(0.5-17.4) \\
{[3.0-11.6]}\end{array}$ & $\begin{array}{l}8.8(0.9-16.0) \\
\quad[4.0-14.0]\end{array}$ \\
\hline $\begin{array}{l}\text { Age at time of investigation, median (min-max) } \\
\text { [lower-upper quartiles] }\end{array}$ & $\begin{array}{l}12.0(1.3-26.0) \\
\quad[5.0-15.7]\end{array}$ & $\begin{array}{l}13.0(1.4-20.0) \\
\quad[9.0-15.1]\end{array}$ \\
\hline Systemic arthritis, number, \% & $15(93.8)$ & $1(6.2)$ \\
\hline Polyarthritis, RF-, number, \% & $7(36.8)$ & $12(63.2)$ \\
\hline Oligoarthritis, number, \% & $3(7.9)$ & $35(92.1)$ \\
\hline Enthesitis-related arthritis, number, \% & $6(22.2)$ & $21(77.8)$ \\
\hline Polyarthritis, RF+, number, \% & $1(50.0)$ & $1(50.0)$ \\
\hline $\begin{array}{l}\text { Average number of arthritis at time of investigation, } \\
\text { median (min-max) [lower-upper quartiles] }\end{array}$ & $\begin{array}{l}3.0(0.0-32.0) \\
{[1.0-11.0]^{*}}\end{array}$ & $\begin{array}{l}1.5(0.0-29.0) \\
\quad[1.0-2.0]\end{array}$ \\
\hline Low activity, number of cases & 3 & $47^{*}$ \\
\hline Moderate activity, number of cases & 15 & 16 \\
\hline High activity, number of cases & $12^{*}$ & 2 \\
\hline One unfavourable prognostic criterion, number of cases & 11 & 28 \\
\hline $\begin{array}{l}\text { Two or more unfavourable prognostic criteria, number } \\
\text { of cases }\end{array}$ & $20^{*}$ & 10 \\
\hline
\end{tabular}

${ }^{*} p<0.05$ 
Table II. Laboratory investigations in patients with refractory and non-treatment-refractory JIA disease course

\begin{tabular}{|lcc|}
\hline Factors & $\begin{array}{c}\text { Patients with refractory JIA } \\
N=33\end{array}$ & $\begin{array}{c}\text { Patients with non-refractory JIA } \\
N=72\end{array}$ \\
\hline $\mathrm{sCD} 25, \mathrm{pg} / \mathrm{ml}$ & $465.3(24.3-4140.8)[360.1-970.7]^{*}$ & $373.6(0-1870)[264.5-523.7]$ \\
\hline $\mathrm{s} I \mathrm{~L}-6 \mathrm{R}, \mathrm{pg} / \mathrm{ml}$ & $8167.6(793.2-11425.4)[7652.3-8594.2]$ & $8336.6(6649.5-13215)[7757.6-8900.3]$ \\
\hline $\mathrm{IL}-1, \mathrm{pg} / \mathrm{ml}$ & $1.9(0.5-90.4)[1.1-3.5]$ & $1.2(0.5-56.5)[0.8-2.8]$ \\
\hline $\mathrm{IL}-6, \mathrm{pg} / \mathrm{ml}$ & $66.2(0-852.2)[33.3-152.5]^{*}$ & $6.1(0-299.1)[0-23.9]$ \\
\hline $\mathrm{IL}-17, \mathrm{pg} / \mathrm{ml}$ & $7.8(0-595.7)[0-28.3]$ & $0(0-4944.7)[0-7.2]$ \\
\hline $\mathrm{IL}-10, \mathrm{pg} / \mathrm{ml}$ & $7.5(0-63.5)[4.2-11.9]$ & $7.8(0-180)[2.4-18.4]$ \\
\hline $\mathrm{IL}-4, \mathrm{pg} / \mathrm{ml}$ & $1.4(0.2-1378.4)[0.4-32.6]$ & $1.3(0.2-2160.6)[0.5-10.2]$ \\
\hline $\mathrm{IL}-8, \mathrm{pg} / \mathrm{ml}$ & $7.3(0-435.1)[2.1-14.1]$ & $6(0.1-467.4)[2.3-14.9]$ \\
\hline $\mathrm{IFN}-\gamma, \mathrm{pg} / \mathrm{ml}$ & $6.1(0-49.9)[0-12.2]$ & $3.1(0-501.2)[0-13.6]$ \\
\hline TNF- $\alpha, \mathrm{pg} / \mathrm{ml}$ & $1.1(0-130.1)[0-22.3]$ & $2.3(0-1325.8)[0-16.9]$ \\
\hline $\mathrm{IL}-1 \mathrm{R} a, \mathrm{pg} / \mathrm{ml}$ & $2039.7(451.2-23683.8)[1164.1-7758.5]^{*}$ & $1077.8(189.8-9852)[566.3-1983.1]$ \\
\hline sTNF-R1, pg/ml & $1826.3(838.7-17650.8)[1343.7-3715.8]^{*}$ & $1516.2(579.7-2800.2)[943.5-1765.7]$ \\
\hline
\end{tabular}

${ }^{*} p<0.05$

parametric data was done with the Mann-Whitney test, which does not require a check for normality of distribution and is suitable for comparison of small samples. The Spearman method was used for calculation of pair correlation coefficients. Statistical data analysis was conducted at the Chair of Social Medicine, Economics and Healthcare Management of the Lviv Danylo Halytsky National Medical University. For construction of the treatment-refractory JIA course probability prognostic model, a logistic regression method was used. This method allows detection of dependency of the characteristic of interest (formation of treatment-refractory disease course) on a combined action of a set of other variables (factors) and prediction of its change with changes in other variables (factors) included in the regression model.

Probability of treatment-refractory course formation (p), subject to factors chosen by us, was calculated using the formula (1):

$$
p=\frac{1}{1+e^{-2}}{ }^{*} 100 \%
$$

where $e=2,72 \ldots$ - the base of the natural logarithm, $Z$ - a value calculated according to formula (2):

$$
Z=b_{1} x_{1}+b_{2} x_{2}+\ldots b_{n} x_{n}+K
$$

where $b_{i}$ - coefficients of independent factors,

$$
x_{n} \text { - independent factors, }
$$$$
K-\text { a constant. }
$$

Theoretically $p$ may have a value between $0 \%$ (an impossible event) to 100\% (an event that always happens).

\section{Results of investigation}

Clinical and laboratory characteristics of investigated groups are presented in Table I. The comparison of groups of IIA patients with a refractory and a non-treatment-refractory disease course revealed that a refractory course develops in patients with high JIA activity at disease onset $(p=0.006)$. Children with a low level of JIA activity have a favourable prognosis of disease course $(p=0.000004)$. The analysis of results showed that a treatment-refractory disease course developed in patients who had two or more factors of a poor disease course at the disease onset $(p=0.0001)$ (Table I). Patients with a treatment-refractory disease course showed a statistically significant increase in levels of IL-6, IL-1Ra, sTNF-R1 and SCD25 in comparison with group of patients with a non-treatment-refractory JIA disease course (Table II).

Overall during this study 20 factors were selected which, according to literature data and personal observations, can influence formation of a treatment-refractory JIA disease course. Spearman's paired correlation coefficient between the named factors and development of a treatment-refractory disease course was calculated and data are depicted in Table III. It was established that 8 factors out of 20 analysed have a statistically significant correlation with the development of a treatment-refractory disease course, although none of these factors showed a strong correlation. Additionally it was established that just two factors have a statistically significant preventive role in the development of a treatment-refractory disease course, namely the oligoarticular subtype of JIA and low disease activity, while 
Table III. Correlation between refractory JIA disease course and risk factors

\begin{tabular}{|c|c|c|c|}
\hline No. & $\begin{array}{l}\text { Risk factors of } \\
\text { refractory disease } \\
\text { course formation }\end{array}$ & $\begin{array}{c}\text { Rank } \\
\text { correlation } \\
\text { coefficient }\end{array}$ & $\begin{array}{l}\text { Statistical } \\
\text { reliability } \\
\text { ( } p \text { value) }\end{array}$ \\
\hline 1 & Systemic JIA & 0.63 & $<0.05$ \\
\hline 2 & $\begin{array}{l}\text { JIA, polyarthritis, } \\
\text { RF-negative }\end{array}$ & 0.05 & $>0.05$ \\
\hline 3 & JIA, oligoarthritis & -0.38 & $<0.05$ \\
\hline 4 & $\begin{array}{c}\text { Enthesitis-related } \\
\text { JIA }\end{array}$ & -0.12 & $>0.05$ \\
\hline 5 & $\begin{array}{l}\text { Presence of poor } \\
\text { prognostic factors }\end{array}$ & 0.52 & $<0.05$ \\
\hline 6 & Low activity & -0.52 & $<0.05$ \\
\hline 7 & Moderate activity & 0.24 & $<0.05$ \\
\hline 8 & High activity & 0.46 & $<0.05$ \\
\hline 9 & $\mathrm{sCD} 25, \mathrm{pg} / \mathrm{ml}$ & 0.25 & $<0.05$ \\
\hline 10 & IL-6R, pg/ml & -0.09 & $>0.05$ \\
\hline 11 & $\mid \mathrm{L}-1, \mathrm{pg} / \mathrm{ml}$ & 0.17 & $>0.05$ \\
\hline 12 & $\mathrm{IL}-6, \mathrm{pg} / \mathrm{ml}$ & 0.55 & $<0.05$ \\
\hline 13 & $\mathrm{IL}-17, \mathrm{pg} / \mathrm{ml}$ & 0.17 & $>0.05$ \\
\hline 14 & IL-10, pg/ml & -0.02 & $>0.05$ \\
\hline 15 & $\mid \mathrm{L}-4, \mathrm{pg} / \mathrm{ml}$ & -0.02 & $>0.05$ \\
\hline 16 & IL-8, pg/ml & 0.01 & $>0.05$ \\
\hline 17 & IFN, pg/ml & 0.06 & $>0.05$ \\
\hline 18 & TNF, pg/ml & -0.04 & $>0.05$ \\
\hline 19 & IL-1 RAG, pg/ml & 0.11 & $>0.05$ \\
\hline 20 & TNF-R1, pg/ml & 0.12 & $>0.05$ \\
\hline
\end{tabular}

six other factors have a provocative role. It was proved that systemic disease subtype, moderate and high disease activity, and presence of factors of poor prognosis have a statistically significant link with development of a treatment-refractory disease course. Statistical analysis with calculation of Spearman's paired correlation coefficients between named factors and development of a treatment-refractory IIA course revealed the existence of a statistically significant link between treatment-refractory disease course and cytokine levels, namely SCD25 and IL-6.

The logistic regression method was used to determine statistically significant risk factors of development of a treatment-refractory JIA disease course, generated by combined action of the named factors. All above-mentioned clinical factors were included in the logistic model, plus CD25 and IL-6 - two biomarkers, out of the whole group of laboratory factors, which had a statistically significant provocative link with increased risk of treatment-refractory JIA development. Regres-
Table IV. Regression coefficient values for development of treatment-refractory JIA disease course, according to logistic regression method

\begin{tabular}{|c|c|c|c|}
\hline No. & Factors & $\begin{array}{l}\text { Symbolic } \\
\text { character }\end{array}$ & $\begin{array}{l}\text { Regression } \\
\text { coefficient }\end{array}$ \\
\hline 1 & $\begin{array}{l}\text { Systemic } \\
\text { arthritis }\end{array}$ & A & 37.774 \\
\hline 2 & $\begin{array}{l}\text { JA, polyarthri- } \\
\text { tis, RF-negative }\end{array}$ & B & 0.512 \\
\hline 3 & $\begin{array}{l}\text { JA, oligoar- } \\
\text { thritis }\end{array}$ & C & -0.773 \\
\hline 4 & $\begin{array}{c}\text { Enthesitis-relat- } \\
\text { ed JIA }\end{array}$ & D & 0.085 \\
\hline 5 & $\begin{array}{c}\text { Presence of } \\
\text { poor prognostic } \\
\text { factors }\end{array}$ & E & 0.590 \\
\hline 6 & Low activity & $\mathrm{F}$ & 16.781 \\
\hline 7 & $\begin{array}{l}\text { Moderate } \\
\text { activity }\end{array}$ & G & 18.974 \\
\hline 8 & High activity & $\mathrm{H}$ & 19.260 \\
\hline 9 & sCD25, pg/ml & I & 0.0001 \\
\hline 10 & $\mid \mathrm{L}-6, \mathrm{pg} / \mathrm{ml}$ & J & 0.007 \\
\hline 11 & Constant & & -20.043 \\
\hline
\end{tabular}

sion coefficient values for ten factors, combined action of which have a statistically significant effect on development of treatment-refractory JIA disease course, are shown in Table IV.

After inserting the results obtained by logistic regression method into the formula, a Z-value was obtained - one that enables calculation of probability of treatment-refractory JIA disease course:

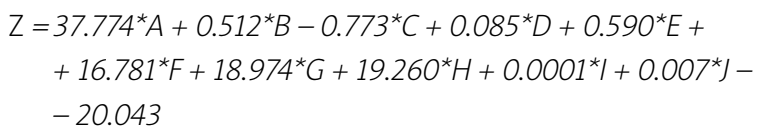

The validity of calculated coefficients was checked with the Wald test and the validity of the entire model with the chi-square test. The obtained value of 78.151 indicates that the model is valid with the probability of a mistake less than $0.1 \%(p<0.001)$. At the same time the obtained value of Nagelkerke $R$ square, which is 0.737 , indicates that factors included in the model precondition formation of a refractory JIA course for $73.7 \%$, while for $26.3 \%$ formation of the named pathology is caused by other factors.

Based on the obtained Z-value, using the formula, an individual risk of treatment-refractory JIA course can be calculated for any specific patient. 
Two examples of individual risk (IR) calculations for development of a treatment-refractory JIA course are provided. Patient 1, diagnosis: JIA, oligoarticular subtype, number of poor prognostic factors at disease onset - 0 , activity - moderate, value of sCD25 = $1597.5 \mathrm{pg} / \mathrm{ml}$, and $\mathrm{IL}-6=15.8 \mathrm{pg} / \mathrm{ml}$. Prognostic risk of refractory JIA development: $I R=17.32 \%$. This result coincides with the results of clinical follow-up: patient 1 did not develop a treatment-refractory disease course.

Patient 2, diagnosis: JA, polyarticular subtype with negative rheumatoid factor, number of poor prognostic factors at disease onset - 2, activity - moderate, value of $\mathrm{sCD} 25=418.0, \mathrm{pg} / \mathrm{ml}$, and $\mathrm{IL}-6=32.7 \mathrm{pg} / \mathrm{ml}$. Prognostic risk of refractory $J I A: I R=70.81 \%$. This result coincides with the results of clinical follow-up: patient 2 developed treatment-refractory JIA.

For calculation of risk of treatment-refractory JIA course a Microsoft Excel application was developed, which enables one to establish the probability of a refractory JIA course in any specific patient, based on 10 factors. The application automatically calculates the risk of a treatment-refractory disease course and presents it graphically (Figs. 1, 2).

\section{Discussion}

The aim of this study was to develop an application for automatic calculation of individual risk of treatment-refractory JIA disease course formation. The fol-

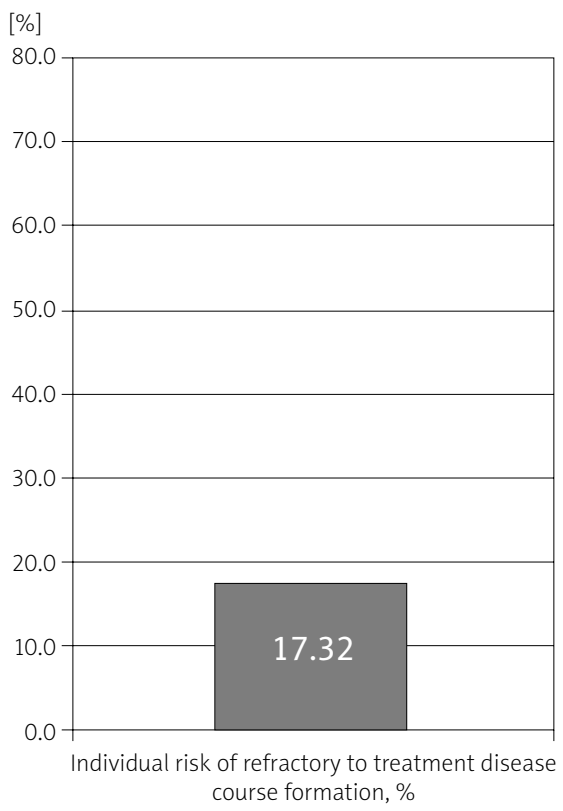

Fig. 1. Application for calculation of treatment-refractory JIA disease course risk based on 10 factors (example 1). lowing disease predictors were included in the study: JIA subtypes, disease activity, presence of clinical factors of poor prognosis and cytokine profile data. Current studies, investigating predictors of therapeutic outcome in JA patients, search not just for clinical characteristics of the disease course, but also for gene expression profiling in peripheral blood as a prognostic test for these patients. Technological spin-offs from the Human Genome Project studying gene expression profiling in peripheral blood promise that individualized therapies can be developed in future, based on genomic data [7]. However, current medical practice still awaits the development of affordable, easy to use methods that can predict disease course in JIA patients, based on clinical data. It has been shown in a number of studies that prognosis depends on the disease subtype. In particular, it was found that polyarticular and systemic variants, in comparison to other JIA variants, have unfavourable sequelae $[8,9]$, which correlates with the results of our study. In our study we did not take into consideration other important factors, in particular age at start of the disease treatment and disease duration before commencement of treatment. The results of the Geikowski et al. study [9] showed that parameters predicting a high-grade response to a 6-month course of etanercept in JIA patients were younger age at disease onset and shorter duration of the disease at commencement of treatment. The Albarouni et al. study [10] revealed a statistically signifi-

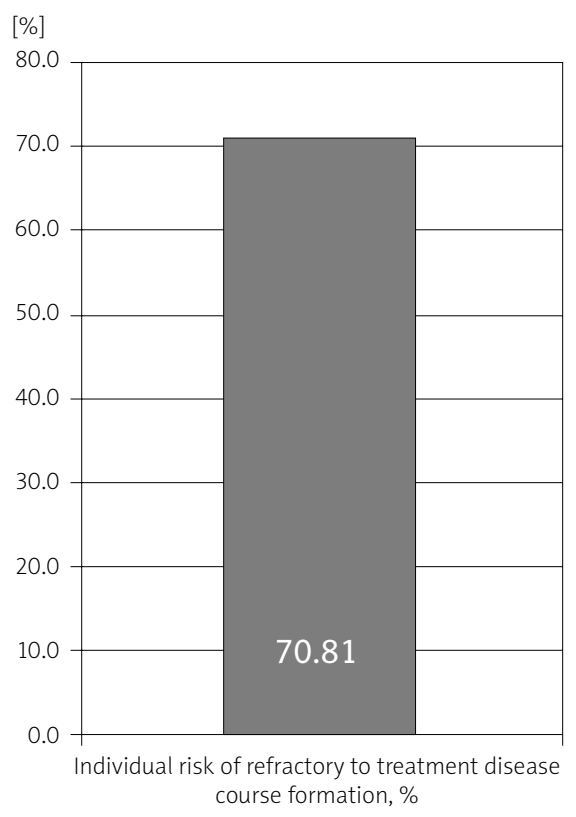

Fig. 2. Application for calculation of treatment-refractory JIA disease course risk based on 10 factors (example 2). 
cant correlation between disease duration of less than 1 year, higher numbers of active joints, lower numbers of tender joints, presence of morning stiffness, and a strong therapeutic response to MTX in JIA patients 12 months after beginning MTX treatment. Our study takes into account clinical factors of poor prognosis, which are presented in the American College of Rheumatology (ACR) 2011 recommendations [6]. Another predictor of poor prognosis included in our study was JIA activity, which we defined according to ACR recommendations and the Unified clinical protocol of medical care to children with juvenile arthritis in Ukraine [5]. The results obtained confirm the existence of statistically significant link between disease activity and IA prognosis. The current study revealed that a treatment-refractory disease course was seen in IIA patients with moderate and high disease activity levels. Apart from clinical predictors of JIA course, two cytokines included in our model - IL-6 and SCD25 - appeared to have a statistically significant link with poor disease prognosis. As a consequence of our study an application for automatic calculation of the percentage reflecting risk for development of treatment-refractory JIA disease course was developed. Use of this application enables prediction of JIA disease course at the time of the JIA diagnosis. It may serve as a basis for making a personalized treatment choice in children with JIA.

\section{Conclusions}

In patients with a treatment-refractory IIA disease course a high disease activity at onset was found $(p=0.006)$, presence of two or more poor prognostic criteria at onset of the disease $(p=0.0001)$ and a statistically significant increase in levels of IL-6 (> $66.2 \mathrm{pg} / \mathrm{ml})$, IL-1Ra (> $2039.7 \mathrm{pg} / \mathrm{ml}$ ), sTNF-R1 (> $1826.3 \mathrm{pg} / \mathrm{ml}$ ) and sCD25 (> $465.3 \mathrm{pg} / \mathrm{ml})$.

We determined that systemic subtype of the disease, moderate and high disease activity, presence of factors of poor disease course and SCD25 and IL-6 levels are statistically significant factors of treatment-refractory disease course development.

A Microsoft Excel application was developed for automatic calculation of risk of treatment-refractory JIA disease course formation in a specific patient based on 10 factors.

Use of an application for automatic calculation of risk of treatment-refractory JIA development enables prediction of JIA disease course in patients at disease onset and to personalize the treatment protocol.

\section{References}

1. Wallace CA, Giannin EH, Spalding SJ, et al. Trial of early aggressive therapy in polyarticular juvenile idiopathic arthritis. Arthritis Rheum 2012; 64: 2012-2021.

2. Vastert SJ, de Jager W, Noordman BJ, et al. Effectiveness of first line use of recombinant IL-1RA treatment in steroid naive systemic juvenile idiopathic arthritis: results of a prospective cohort study. Arthritis Rheum 2014; 66: 1034-1043.

3. Albers HM, Wessels JA, van der Straaten RJ, et al. Time to treatment as an important factor for the response to methotrexate in juvenile idiopathic arthritis. Arthritis Rheum 2009; 61: 46-51.

4. Petty RE, Southwood TR, Manners P, et al. International League of Associations for Rheumatology classification of juvenile idiopathic arthritis: second revision, Edmonton, 2001. J Rheumatol 2004; 31: 390-392.

5. Unified clinical protocol of medical help to children with juvenile arthritis, Kyiv, 2012. Order of Ministry of Healthcare in Ukraine No 832 dated 22 October 2012. Contemporary Paediatrics 2012; 6: 19 (Ukrainian).

6. Beukelman T, Patkar NM, Saag KG, et al. 2011 American College of Rheumatology recommendations for the treatment of juvenile idiopathic arthritis: initiation and safety monitoring of therapeutic agents for the treatment of arthritis and systemic features. Arthritis Care Res (Hoboken) 2011; 63: 465482.

7. Jiang K, Sawle AD, Frank MB, et al. Whole blood gene expression profiling predicts therapeutic response at six months in patients with polyarticular juvenile idiopathic arthritis. Arthritis Rheum 2014; 66: 1363-1371.

8. Packham JC, Hall MA, Pimm TJ. Long-term follow-up of 246 adults with juvenile idiopathic arthritis: predictive factors for mood and pain. Rheumatology 2002; 41: 1444-1449.

9. Geikowski T, Becker I, Horneff G; German BIKER Registry Collaborative Study Group. Predictors of response to etanercept in polyarticular - course juvenile idiopathic arthritis. Rheumatology (Oxford) 2014; 53: 1245-1249.

10. Albarouni M, Becker I, Horneff G. Predictors of response to methotrexate in juvenile idiopathic arthritis. Pediatr Rheumatol Online J 2014; 13: 12-35.

The authors declare no conflict of interest. 